\title{
The Effect of Gender and Speech Task on Cepstral- and Spectral-Measures of Korean Normal Speakers
}

\author{
Seong Hee Choi ${ }^{1,2,3}$, Chul-Hee Choi ${ }^{1,2,3}$ \\ 'Department of Audiology and Speech-Language Pathology, ${ }^{2}$ Research Institute of Biomimetic Sensory Control, \\ ${ }^{3}$ Catholic Hearing Voice Speech Center, Catholic University of Daegu, Gyeongsan, Korea \\ 한국 정상 화자의 캡스트럼과 스펙트럼 측정치의 성별과 발화 과제 효과 \\ 최 성 희 ${ }^{1,2,3} \cdot$ 최 철 희 ${ }^{1,2,3}$ \\ 대구가톨릭대학교 바이오메디대학 언어청각치료학과', 생체모방감각제어연구소 ${ }^{2}$, 가톨릭 청각음성언어센터 $^{3}$
}

\begin{abstract}
Purpose: The purpose of this study was to explore the effects of speech tasks (vowel vs. continuous speech) and gender on cepstral and spectral measurement. Methods: Fifty-one young adults with normal voice participated and four cepstral-and spectral parameters [cepstral peak prominence (CPP), CPPSD, L/H ratio, L/H ratio SD] were obtained using ADSVTM on seven Korean vowels (/al, / / /, lil, /o/, / $\mathrm{u} /, / \mathrm{m} /, / \Lambda /)$ and two standardized paragraphs ('fall' \& 'walk'). Results: Significant main effects of both gender and vowel type were found. Males had significantly greater mean CPPs than females and greater CPPs for low vowel /a/ than high vowels (/i/ and /U/). No effect of continuous speech type on CPPs and $\mathrm{L} / \mathrm{H}$ ratio, but gender had significant effect on the $\mathrm{L} / \mathrm{H}$ ratio (greater $\mathrm{L} / \mathrm{H}$ ratio for males in both continuous speech tasks). In addition, vowels had significantly greater CPP and L/H ratio than continuous speech including various phonemes. There was no relationship between 'walk' and 'fall' in CPP whereas higher correlation was presented between 'walk' and 'fall' in $\mathrm{L} / \mathrm{H}$ ratio. In normal voice, no evidence provided that /a/vowel had any relationships with both standardized paragraphs in CPP reflecting overall voice quality or severity of voice disorders. Conclusion: The results of this study indicate that cepstral- and spectral-based measures for normative data need to consider vowel type and gender. Furthermore, gender differences should also be considered for $\mathrm{L}$ $\mathrm{H}$ ratio spectral-based measurement in continous speech.
\end{abstract}

Key Words: Cepstral, Spectral, Vowel, Continuous speech, Gender.

Received: June 12, 2016 / Revised: July 6, 2016 / Accepted: July 14, 2016

Correspondence: Chul-Hee Choi, Department of Audiology and Speech-Language Pathology, Research Institute of Biomimetic Sensory Control, and Catholic Hearing Voice Speech Center, Catholic University of Daegu, 13-13 Hayang-ro, Hayang-eup, Gyeongsan 38430, Korea

Tel: +82-53-850-2541 / Fax: +82-53-359-0780 / E-mail: cchoi@cu.ac.kr

\section{INTRODUCTION}

청지각적 음질 평정은 일반적으로 모음연장발성이나 연결발 화를 통해 이루어지며, 국내에서는 모음연장발성이나 표준화문 단 읽기가 진단이나 평가에 주로 활용된다(Choi, 2013). 모음연 장발성은 바쁜 임상에서 음성의 비정상적인 정도를 평가하는 데 일반적으로 사용되고 있으나, 연결발화는 전형적인 일상생활의 발화 패턴을 반영하고 매일의 일상생활에서 사용하는 환자의 음질을 잘 반영하므로 그 중요성이 강조되고 있다(Bele, 2005; Parsa \& Jamieson, 2001). 청지각적 평정과 마찬가지로, 음향학
적 측정치도 다양한 발화 과제를 통해 얻어야 하지만, 음향학적 분석은 시간에 따른 주기나 강도의 일관성이 필수적이다. 다차 원 음성측정기(Multi Di-mensional Voice Program)와 같은 대 부분의 음성분석프로그램은 모음 연장발성 분석은 가능하나 연결발화의 분석에는 상당한 제약이 있다.

최근 연결발화를 객관적으로 평가하기 위해 주파수 기반 분 석인 스펙트럼이나 캡스트럼과 같은 음향학적 분석이 널리 사 용되고 있다(Maryn et al., 2009). 변동률 분석과 달리, 캡스트 럼 분석치들은 주파수영역에서 성대의 진동 신호와 성도의 공 명주파수를 분리하여 정확한 기본주파수 검출을 요하지 않으 
므로(Noll, 1967), 모음뿐 아니라 불안정한 음도변화를 포함하 는 연결발화도 음향학적 분석이 가능하며, 주기적인 음성 신호 뿐 아니라 매우 비주기적인 음성 신호도 분석이 가능한 장점을 지닌다(Heman-Ackah et al., 2003). 특히, 안정된 음도와 강도 를 가정으로 하는 전통적인 시간 기반 음향지표인 변동률 분석 에 비해 캡스트럼 분석은 변동률 분석보다 청지각적 음질 평정 상관이 더 높고, 모음연장발성뿐 아니라 연결발화에서 정상 음 성과 장애 음성을 잘 감별하는 음향적 지표였다(Awan \& Roy, 2006; Eadie \& Baylor, 2006; Halberstam, 2004; Lowell et al., 2011; Lowell et al., 2013; Wolfe \& Martin, 1997; Wolfe et al., 2000). 음향학적 변동률 분석에 있어서 모음 유형의 효과 연구에 따르면, 강도변동률에서만 유의한 차이를 보였으며, 저후설 /아/ 모음이 다른 모음에 비해 통계적으로 유의하게 높은 강도변동률을 나타내었다(Choi \& Choi, 2015). 그러나, 시간 기 반의 변동률 분석에 비해 정확한 기본주파수 추출을 요하지 않 는 캡스트럼이나 스펙트럼 분석에서 모음의 효과는 아직 알려지 지 않았다. 최근 국외에서 다양한 모음과 연결발화에 따른 캡 스트럼 분석에 대한 연구가 있었으나(Awan et al., 2012; Lowell \& Hylkema, 2016), 한국어와는 다르므로 이를 그대로 적용 하기에는 무리가 있다.

현재까지 캡스트럼에 대한 국내의 음향학적 연구는 주로 모 음연장발성에 대한 연구가 대부분이었으며(Choi \& Choi, 2014; Shim et al., 2014), 다양한 모음이나 성별을 고려하지 못하였다. Shim et al.(2014)의 연구에서는 후두전적출술을 받은 식도발 성화자 13명과 노인화자 13명을 대상으로 모음/아/ 발성으로 캡 스트럼과 스펙트럼 분석을 실시하였으며, 대상자는 모두 남성이 었다. Choi \& Choi(2014)의 연구에서도 /아/ 모음만을 사용하 여 음성의 중증도에 따른 장애음성의 스펙트럼과 캡스트럼 측 정치를 시간기반 분석치와 비선형동적분석치와 비교하였다.

한편, 연결발화에 대한 음향학적 연구로는 6어절로 구성된 문장으로 16 85세의 11 명의 마비말장애 화자와 성과 연령을 일 치시킨 11 명의 정상화자를 대상으로 캡스트럼과 스펙트럼 분석 으로 연결발화를 분석한 연구가 있었다(Seo \& Seong, 2013). 한편, Lee(2011)의 연구에서는 표준 문단 '산책(Jeong, 1994)' 중 첫 두 문장을 사용하여 연속구어에 대한 음향적 분석을 실시 하였으며 장구간 평균 스펙트럼 분석, 스펙트럼 기울기 등의 음 향학적 변수를 측정하였다. 이와 같이 국내 선행 연구에서는 다양한 모음이나 연속구어 과제 및 성별 차이를 고려한 캡스트 럼이나 스펙트럼 분석치에 대한 충분한 근거가 제시되어 있지 않다. 따라서, 본 연구의 목적은 성별과 다양한 한국어 말소리 문맥 간 캡스트럼과 스펙트럼 측정치에 유의한 차이가 있는지 규명해 보고자 한다. 또한, 연결발화가 다양한 말소리의 음향적 정보를 포함하므로 현재 사용되는 두 개의 표준화문구 간에 캡
스트럼이나 스펙트럼 측정치에 차이가 있는지 살펴보고 연결발 화의 음향학적 측정치를 예측할 수 있는 모음과 연결발화의 상 관성을 살펴보고자 한다.

\section{MATERIALS AND METHODS}

\section{연구 대상}

본 연구에 참여한 대상자는 만 20 30세 정상 청년층 51명(여 자 34명, 남자 17명)을 대상으로 하였다. 대상자는 5년 이상 음 성평가를 해온 1 급 언어재활사 2 명에 의해 청지각적 평정인 GR$\mathrm{BAS}$ 에서 G가 “'”이며 이비인후과의사 판독에 의해 후두내시경 소견 상 정상소견을 보이고 최근 상기도감염이나 후두질환이 없고 흡연 경력이 없는 사람을 대상으로 하였다.

\section{연구 절차}

\section{말과제 및 음성자료 수집}

음성자료는 소음이 통제된 음성검사실에서 수집하였다. 녹음 은 입으로부터 $10 \mathrm{~cm}$ 떨어진 위치에서 90도 각도로 고정된 단일 지향성 다이나믹 유형의 마이크(D7 Vocal., AKG, Vienna, Austria)를 사용하였으며, CSL프로그램(Model 4300B; Pentax Medical Company, Lincoln Park, NJ, USA)을 사용하여 샘플 링 속도를 $44,100 \mathrm{~Hz}$ 의 표본추출비율로 모음과 연결발화를 녹 음하였다.

모음연장발성과제는 Shin \& Cha(2003)의 구어체계에 입각 한 7개의 한국어 단모음 체계를 사용하였다(Table 1). 편안한 음도와 강도에서 '하나 둘 셋' 숫자세기 후 각 모음을 3초간 3번 반복하여 발성하도록 하였다. 모음의 유형은 검사자마다 다른 순서로 무작위로 녹음하였으며, 분석치는 3번 반복한 것의 평균 값을 사용하였다. 표준화 문구는 표준 문단 '산책(Jeong, 1994)' 과 '가을(Kim, 1996)'을 처음부터 끝까지 평상시의 음도와 높이 로 각각 한 번씩 읽도록 하였다. 문단 읽기 중 잘못 읽은 것은 다 시 읽도록 지시하였으며 녹음 후 잘못 읽은 것은 다시 듣기 재생 후 편집하여 수정된 문단 읽기를 최종 저장하였다. 녹음된 파일 은 총 1,173 개 $(7$ 개 모음 $\times 3$ 번 $\times 2$ 개 문단 $\times 51$ 명 $)$ 의 음성 파일 로 저장되었다.

Table 1. Vowel tasks (Korean 7 vowels in spoken language)

\begin{tabular}{lccc}
\hline & Front & \multicolumn{2}{c}{ Back } \\
\cline { 2 - 4 } & Uunround & Round & Unround \\
\hline High & $/ \mathrm{i} /$ & $/ \mathrm{u} /$ & $/ \mathrm{u} /$ \\
Mid & $/ \varepsilon /$ & $/ \mathrm{o} /$ & $/ \wedge /$ \\
Low & & & $/ \mathrm{a} /$ \\
\hline
\end{tabular}




\section{캡스트럼 및 스펙트럼 분석}

정상 성인을 대상으로 한 모음과 연결발화의 캡스트럼 및 스 펙트럼 분석을 위해 $\mathrm{ADSV}^{\mathrm{TM}}$ (Analysis of Dysphonia in Speech and Voice, Model 5109, Kay Pentax Medical, Montvale, $\mathrm{NJ}, \mathrm{USA}$ )의 프로그램을 사용하였다. 모음은 처음과 끝부분을 제외한 가운데 부분인 1초를 분석대상으로 하였고 평균값을 사용하였으며, 연결발화인 표준문단은 각 문단의 처음과 끝부 분을 분석 대상으로 하였다. ADSV프로그램에서 자동 음성 부 분 검출 방식을 선택하여 2개의 캡스트럼 분석치 cepstral peak prominence (CPP) (dB), CPP_SD (dB)와 2개의 스펙트 럼 분석치 low-high spectral ratio (L/H ratio) (dB), L/H ratio_ $\mathrm{SD}(\mathrm{dB})$ 를 측정하였다. $\mathrm{CPP}(\mathrm{dB})$ 는 전체 캡스트럼의 회귀선과 cepstral peak간 강도의 차이를 말하며, 비정상적인 음질일수 록 CPP 값이 작다(Hillenbrand \& Houde, 1996; Lowell et al., 2012).

스펙트럼 분석인 $\mathrm{L} / \mathrm{H}$ ratio는 $4,000 \mathrm{~Hz}$ 를 기준으로 $4,000 \mathrm{~Hz}$ 위아래의 평균 에너지의 비율을 의미하며, L/H ratio_SD는 L/ $\mathrm{H}$ ratio의 표준편차이다.

\section{통계분석}

수집된 자료의 통계 분석은 IBM SPSS Statistics $19.0^{\mathrm{TM}}$ (IMB, New York, NY, USA)을 사용하였으며, 성별과 모음문맥과 연 결발화 문맥에 대한 $\mathrm{CPP}$ 와 $\mathrm{L} / \mathrm{H}$ ratio값은 기술통계를 이용하 여 평균과 표준편차를 산출하였다. 성별과 모음문맥 및 성별과 연결발화 문맥 간에 따른 $\mathrm{CPP}, \mathrm{L} / \mathrm{H}$ ratio 측정치의 차이를 비 교하기 위해 개체 내 요인은 모음 과제(7수준) 혹은 연결발화(2 수준)과제, 개체 간 요인은 성별(남녀 두 수준)로 하는 반복측
정 혼합 분산분석(a repeated-measures mixed ANOVA)을 각 각 실시하였다. 개체 간 반복측정분석에 대한 통계검정은 Mauchly의 구형성 검정에 의해 구형성이 가정된 경우는 구형 성 가정값을 사용하였으며, 구형성 가정을 만족하지 않는 경우 는 Greenhouse-Geisser로 수정된 자유도와 F값을 보고하였 다. 또한, 개체 내 효과 검정 결과, 통계적으로 유의미한 경우, 개체 내 대비검정을 실시하여 유의성 검정을 실시하였다. 성별 에 따른 모음과 연결발화 간 $\mathrm{CPP}, \mathrm{L} / \mathrm{H}$ ratio 측정치의 차이를 분석하기 위해 이원분산분석(two-way ANOVA)을 실시하였 으며, 발화 문맥(모음 Vs. 연결발화)에 따른 캡스트럼 및 스팩트 럼 측정치와 간 상관관계는 피어슨 상관분석(Pearson correlation analysis)으로 분석하였으며, 유의수준은 0.05 였다.

\section{RESULTS}

\section{캡스트럼과 스펙트럼 분석의 모음 유형 효과}

모음 문맥에 따른 $\mathrm{CPP}$ 와 $\mathrm{L} / \mathrm{H}$ ratio값의 평균치와 표준편차는 Table 2와 Figure 1과 같다. CPP값은 모음 중 /아/(M = 11.894, $\mathrm{SD}=1.94$ )가 가장 높았으며, /어/ > /에/ > /으/ > /오/ > /이/ > /우/ 순이었다. 반복측정 혼합 분산분석(1개의 집단 간 요인(성별: 2수준)과 1 개의 집단 내 요인(모음의 유형: 7수준) 결과, 성별과 모음 문맥 간 상호작용은 없었으나(F(Greenhouse-Geiser: $3.752,183.829)=1.972, p>0.05)$, 통계적으로 유의미한 모음의 주효과가 있었으며(F(Greenhouse-Geiser: 3.752, 183.829) = 45.792, $p<0.001$; partial $\left.\eta^{2}=0.483\right)$, 성별의 주효과가 있었다 $\left(\mathrm{F}(1,49)=63,150, p<0.001\right.$; partial $\left.\eta^{2}=0.563\right)$. 대응별 비교 결과, /아/와 /에/, /우/, /으/, /어/ 모음은 모든 모음과 유의한 차

Table 2. CPP \& $\mathrm{L} / \mathrm{H}$ ratio measures $(\mathrm{dB})$ based on gender in each vowel task of normal speakers

\begin{tabular}{|c|c|c|c|c|c|}
\hline \multirow{2}{*}{ Vowel } & \multirow{2}{*}{ Gender } & $\mathrm{CPP}(\mathrm{dB})$ & \multirow{2}{*}{$t$} & $\mathrm{~L} / \mathrm{H}$ ratio $(\mathrm{dB})$ & \multirow{2}{*}{$t$} \\
\hline & & $\mathrm{M} \pm \mathrm{SD}$ & & $\mathrm{M} \pm \mathrm{SD}$ & \\
\hline \multirow[t]{2}{*}{$/ \mathrm{a} /$} & M & $14.07 \pm 1.27$ & $9.334^{\dagger}$ & $31.38 \pm 3.69$ & $4.007^{\dagger}$ \\
\hline & F & $10.81 \pm 1.13$ & & $27.44 \pm 3.12$ & \\
\hline \multirow[t]{2}{*}{$\mid \varepsilon /$} & M & $12.72 \pm 1.65$ & $5.870^{\dagger}$ & $28.62 \pm 4.41$ & $3.532^{*}$ \\
\hline & F & $10.19 \pm 1.35$ & & $24.65 \pm 3.45$ & \\
\hline \multirow[t]{2}{*}{ /i/ } & M & $11.06 \pm 2.36$ & $4.198^{\dagger}$ & $26.64 \pm 5.88$ & 1.850 \\
\hline & F & $8.37 \pm 1.69$ & & $23.75 \pm 4.94$ & \\
\hline \multirow[t]{2}{*}{ /o/ } & M & $11.00 \pm 2.36$ & $3.745^{\dagger}$ & $37.55 \pm 4.41$ & -0.373 \\
\hline & $\mathrm{F}$ & $9.02 \pm 1.80$ & & $38.02 \pm 4.18$ & \\
\hline \multirow[t]{2}{*}{$/ \mathrm{u} /$} & M & $10.14 \pm 1.24$ & $4.999^{\dagger}$ & $37.92 \pm 4.44$ & 1.086 \\
\hline & F & $8.28 \pm 1.25$ & & $35.30 \pm 9.40$ & \\
\hline \multirow[t]{2}{*}{ /w/ } & M & $12.08 \pm 1.74$ & $5.756^{\dagger}$ & $32.08 \pm 5.58$ & $3.047^{*}$ \\
\hline & $\mathrm{F}$ & $9.37 \pm 1.50$ & & $28.40 \pm 3.08$ & \\
\hline \multirow[t]{2}{*}{$|\wedge|$} & M & $12.91 \pm 1.17$ & $5.834^{\dagger}$ & $32.68 \pm 3.84$ & 1.523 \\
\hline & $\mathrm{F}$ & $10.78 \pm 1.26$ & & $30.49 \pm 5.26$ & \\
\hline
\end{tabular}

${ }^{*} p<0.01,{ }^{\dagger} p<0.001$. CPP: cepstral peak prominence, L/H ratio: low-high spectral ratio, M: mean, SD: standard deviation 

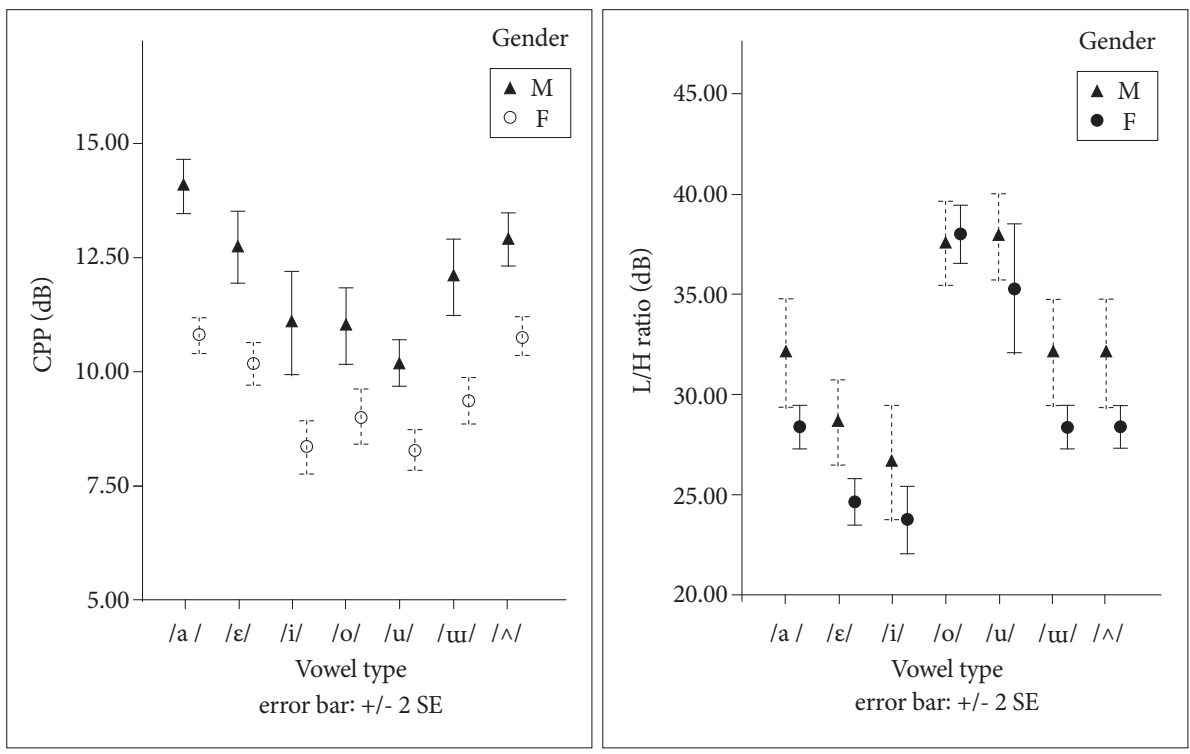

Figure 1. CPP \& $\mathrm{L} / \mathrm{H}$ ratio $(\mathrm{dB})$ measures based on gender and vowel tasks. CPP: cepstral peak prominence, $\mathrm{L} / \mathrm{H}$ ratio: lowhigh spectral ratio.
이를 보였고 $(p<0.01)$, /이/ 모음은 /오/ 모음을 제외한 모든 모음과 차이를 보였다 $(p<0.01)$. 성별의 경우, 남성이 여성에 비 해 통계적으로 유의하게 높은 $\mathrm{CPP}$ 값을 보였으며, 모든 모음에 서 남성이 여성에 비해 유의하게 높았다 $(p<0.001)($ Table 2).

한편, $\mathrm{L} / \mathrm{H}$ ratio값은 /오/ 모음 $(\mathrm{M}=37.55, \mathrm{SD}=4.41)$ 이 가장 높았으며, /우/ > /어/ > /으/ > / 아/ > /에/ > / 이/ 순이었다. 반복 측정 혼합 분산분석 결과, 성별과 모음 유형 간 통계적으로 유 의한 상호작용 효과는 없었으나(F(Greenhouse-Geiser: 3.453,

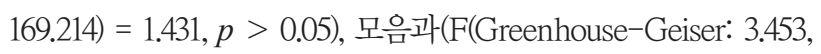
$169.214)=52.807, p<0.001$; partial $\left.\eta^{2}=0.519\right)$ 성별의 주효과가 있었다 $\left(\mathrm{F}(1,49)=9.220, p<0.01\right.$; partial $\left.\eta^{2}=0.158\right)$. 대응별 비교결과, 모음/아/는/으/를 제외하고, 모음/에/는/이/를 제외 하고, 모음/오/는/우/를 제외하고, 모음/어/는/으/를 제외한 모 든 모음과 유의한 차이를 나타내었다 $(p<0.01)$. 성별의 경우, Table 2에서 보는 바와 같이, 모음/아/, /에/, /으/는 남성이 여성 에 비해 유의하게 높았다 $(p<0.001)$.

\section{캡스트럼과 스펙트럼 분석의 연결발화 유형 효과}

연결발화(표준문단 '가을'과 '산책')과제에 따른 $\mathrm{CPP}$ 와 $\mathrm{L} / \mathrm{H}$ ratio값의 평균치와 표준편차를 Table 3과 Table 4에 각각 제시 하였다. 반복측정 혼합 분산분석 결과, $\mathrm{CPP}$ 는 성별과 연결발화 간에 상호작용은 없었으나 $(\mathrm{F}(1,49)=0.276, p>0.05)$, 성별 간 $(\mathrm{F}(1,49)=3.415, p>0.05)$, 연결발화 간에 유의한 차이를 보이 지 않았다 $(\mathrm{F}(1,49)=0.276, p>0.05)$.

이와는 대조적으로, $\mathrm{L} / \mathrm{H}$ ratio에서는 두 표준 문단에서 남성 이 여성에 비해 높은 $\mathrm{L} / \mathrm{H}$ ratio값을 보였다 $(p<0.01)$. 성별과 연결발화 간에 상호작용은 없었고 $(\mathrm{F}(1,49)=0.097, p>0.05)$, 연 결발화 간에도 유의한 차이를 보이지 않았다 $(\mathrm{F}(1,49)=0.003, p$
Table 3. Means and SDs of CPP measures $(\mathrm{dB})$ based on gender for continuous speech tasks

\begin{tabular}{cccc}
\hline Continuous speech & Gender & $\begin{array}{c}\mathrm{CPP}(\mathrm{dB}) \\
\mathrm{M} \pm \mathrm{SD}\end{array}$ & $t$ \\
\hline Fall & $\mathrm{M}$ & $7.01 \pm 1.15$ & 1.191 \\
& $\mathrm{~F}$ & $6.64 \pm 0.99$ & \\
Walk & $\mathrm{M}$ & $6.95 \pm 1.33$ & 1.508 \\
& $\mathrm{~F}$ & $6.48 \pm 0.90$ & \\
\hline
\end{tabular}

Standardized passages: 'Fall' \& 'Walk'. CPP: cepstral peak prominence, SD: standard deviation

Table 4. Means and SDs of $\mathrm{L} / \mathrm{H}$ ratio measures $(\mathrm{dB})$ based on gender for continuous speech tasks

\begin{tabular}{cccc}
\hline Continuous speech & Gender & $\begin{array}{c}\text { L/H ratio }(\mathrm{dB}) \\
\mathrm{M} \pm \mathrm{SD}\end{array}$ & $t$ \\
\hline Fall & $\mathrm{M}$ & $29.03 \pm 1.84$ & $2.476^{*}$ \\
& $\mathrm{~F}$ & $26.55 \pm 3.90$ & \\
Walk & $\mathrm{M}$ & $28.90 \pm 1.95$ & $2.986^{\dagger}$ \\
& $\mathrm{F}$ & $26.64 \pm 2.79$ & \\
\hline
\end{tabular}

Standardized passages: 'Fall' \& 'Walk. ${ }^{*} p<0.05,{ }^{\dagger} p<0.01$. SD: standard deviation, L/H ratio: low-high spectral ratio

$>0.05)$

\section{캡스트럼과 스펙트럼 분석의 구어과제(모음 vs. 연결발화)의 효과}

모음과 연결발화의 $\mathrm{CPP}$ 와 $\mathrm{L} / \mathrm{H}$ ratio측정치의 평균과 표준편 차는 Table 5와 Figure 2와 같다. 캡스트럼과 스펙트럼 측정치 에 대한 성별과 구어과제 간 차이를 분석한 결과, $\mathrm{CPP}$ 는 성별 과 구어과제 간 상호작용 효과가 있어서 $(\mathrm{F}(1,455)=16.060, p<$ 0.001), 주효과는 분석하지 않았다.

반면에, $\mathrm{L} / \mathrm{H}$ ratio는 성별과 구어과제 간 상호작용이 없었으 며 $(\mathrm{F}(1,455)=0.118, p>0.05)$, 성별 $(\mathrm{F}(1,49)=12.985, p<0.001)$ 
과 구어 과제 $(\mathrm{F}(1,49)=19.564, p<0.001)$ 는 모두 유의미한 차 이가 있었다.

\section{모음과 연결발화 간 캡스트럼과 스펙트럼 측정치의 상관}

모음과 표준문단 간 캡스트럼 측정치 $\mathrm{CPP}$ 의 상관관계는 Table 6과 같다. 두 표준문단 간 $\mathrm{CPP}$ 는 유의한 상관관계가 없 었고 $(r=0.102, p=0.477)$, 산책문단은 모음/어/와 낮은 상관을 $(r=0.308, p=0.028)$, 가을문단은 /에/와 /우/ 모음과 통계적 으로 낮은 상관관계를 보였다 $(p<0.05)$.

한편, 스펙트럼 측정치인 $\mathrm{L} / \mathrm{H}$ ratio 경우, 산책문단은 /아/와

Table 5. Means and SDs of CPP, L/H ratio measures for speech tasks (vowel vs. continuous speech)

\begin{tabular}{lccc}
\hline \multirow{2}{*}{ Task } & \multirow{2}{*}{ Gender } & $\mathrm{CPP}(\mathrm{dB})$ & $\mathrm{L} / \mathrm{H}$ ratio $(\mathrm{dB})$ \\
\cline { 2 - 4 } & & $\mathrm{M} \pm \mathrm{SD}$ & $\mathrm{M} \pm \mathrm{SD}$ \\
\hline Vowel & $\mathrm{M}$ & $12.00 \pm 2.03$ & $32.43 \pm 6.36$ \\
& $\mathrm{~F}$ & $9.54 \pm 1.73$ & $29.56 \pm 6.90$ \\
Continuous speech & $\mathrm{M}$ & $6.96 \pm 0.99$ & $28.96 \pm 1.87$ \\
& $\mathrm{~F}$ & $6.74 \pm 1.15$ & $26.60 \pm 3.36$ \\
\hline
\end{tabular}

CPP: cepstral peak prominence, $\mathrm{SD}$ : standard deviation, $\mathrm{L} / \mathrm{H}$ ratio: low-high spectral ratio

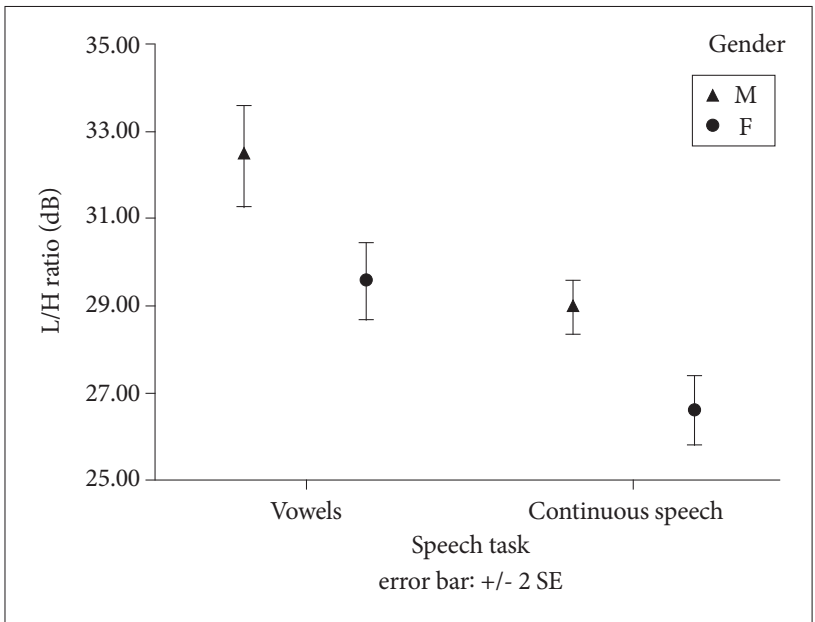

Figure 2. L/H ratio measures based on gender and speech tasks (vowel vs. continuous speech). L/H ratio: low-high spectral ratio, SE: standard error.
/에/모음과 중간 정도의 상관성을 보였으며, /이/와 /으/ 모음과 는 낮은 상관성을 보였다. 가을문단은 /아/ 모음과 중간 정도의 상관성을 $(r=0.503, p=0.000), /$ 으 / 모음과는 낮은 상관성을 보 였다 $(r=0.317, p=0.023) . \mathrm{CPP}$ 와는 달리, 가을과 산책문단 간 에는 강한 상관성을 보였다 $(r=0.748, p=0.000)($ Table 7).

\section{DISCUSSIONS}

본 연구는 캡스트럼이나 스펙트럼 기반 음향학적 분석의 우 수성을 고려하여 정상 성인을 대상으로 다양한 모음뿐 아니라 연결발화 과제를 이용하여 구어 과제와 성별에 따른 CPP나 L/ $\mathrm{H}$ ratio 측정치의 차이를 조사하고자 하였다.

\section{모음 유형의 효과}

본 연구 결과, $\mathrm{CPP}$ 는 성별과 모음에 대한 유의한 효과가 있 었다. 변동률 분석에서는 모음에서 강도변동률만이 차이를 보 였으나(Choi \& Choi, 2015), 본 연구에서는 모음의 유형에 따 라 $\mathrm{CPP}$ 가 유의한 차이를 보였다. 특히 임상에서 가장 일반적으 로 사용되는 /아/모음이 가장 높은 $\mathrm{CPP}$ 값을 나타내었으며, 스 펙트럼에서 조화음 구조가 잘 나타날수록 캡스트럼의 정점은 더 두드러지게 나타나는 데, 저모음/아/가 고모음(/이/, /우/)에 비해 상대적으로 높은 $\mathrm{CPP}$ 값을 보였다. 성별로는 남성이 여성 보다 높은 $\mathrm{CPP}$ 값을 나타내었다. 영어의 경우, 영어 모음/아/는 저-전설 모음에 속하며, 한국어 모음/아/는 저-후설 모음에 속 하므로 언어 간 차이가 있을 수 있으나(Franca, 2012), Awan et al.(2012)의 연구에서는 모음의 유형에 따라 CPP값에 차이를 보 였으며, 본 연구의 결과와 마찬가지로 저모음/아/가 가장 높게 나타났으며, 고모음인 /이/나 /우/가 낮은 CPP값을 보였다.

Titze(1994)에 의하면, 성도 공명으로서 구강은 모음의 제2포 만트에 중요한 역할을 하며, 고모음 산출 시 낮은 제1포르만트 와 높은 제2포르만트를 보이며 제1포르만트와 제2포르만트 간 에 매우 차이가 커서 전반적으로 음성 신호 진폭의 감소를 가 져 온다. 반면 저모음은 높은 제1포르만트와 비교적 낮은 제2포

Table 6. Relationship of CPP measures (dB) among vowels and continuous speech tasks

\begin{tabular}{ccccccccccc}
\hline CPP & Walk & Fall & $/ \mathrm{a} /$ & $/ \varepsilon /$ & $/ \mathrm{i} /$ & $/ \mathrm{o} /$ & $/ \mathrm{u} /$ & $/ \mathrm{u} /$ & $/ \wedge /$ \\
\hline Walk & - & 0.102 & 0.134 & 0.203 & 0.248 & 0.112 & 0.248 & 0.149 & $0.308^{*}$ \\
Fall & 0.477 & - & 0.099 & $0.013^{*}$ & 0.051 & 0.872 & $0.013^{*}$ & 0.091 & 0.091 \\
\hline
\end{tabular}

${ }^{*} p<0.05$. CPP: cepstral peak prominence

Table 7. Relationships of $\mathrm{L} / \mathrm{H}$ ratio measures $(\mathrm{dB})$ among vowels and continuous speech tasks

\begin{tabular}{ccccccccccc}
\hline L/H ratio & Walk & Fall & /a / & $/ \varepsilon /$ & $/ \mathrm{i} /$ & $/ \mathrm{o} /$ & $/ \mathrm{u} /$ & $/ \mathrm{u} /$ & $/ \wedge /$ \\
\hline Walk & - & $0.748^{\dagger}$ & $0.533^{\dagger}$ & $0.459^{\dagger}$ & $0.353^{\dagger}$ & 0.222 & 0.082 & $0.374^{\dagger}$ & 0.182 \\
Fall & $0.748^{\dagger}$ & - & $0.503^{\dagger}$ & 0.242 & 0.229 & 0.215 & 0.125 & $0.317^{*}$ & 0.088 \\
\hline
\end{tabular}

${ }^{*} p<0.05,{ }^{\dagger} p<0.01$ 
르만트를 가지므로 제 1 포르만트와 제 2 포르만트 간의 차이는 적 어 전반적으로 높은 음성신호의 에너지를 가지는 것으로 여겨 진다. 또한, 고모음일수록 구강 개방이 적어서 성도를 통하는 기 류의 저항이 증가하므로 구강 내 후압력이 생기며 이것은 성도 의 전반적 에너지 감폭을 가져오는 반면, 저모음은 구강 개방이 커지므로 소리 압력의 방사 효과를 나타내어 증가된 음성 강도 뿐 아니라 강한 조화음 에너지를 가지는 것으로 보인다(Awan et al., 2012). 성별로 볼 때, 남성은 여성에 비해 많은 조화음을 가질 뿐 아니라 비교적 길고 넓은 성도의 모양을 가지므로 높은 $\mathrm{CPP}$ 값을 가지는 것으로 여겨진다. 이는 음성 치료 시에 /오/나 /우/ 모음과 같은 모음이 다른 평순모음에 비해 올바른 공명된 소리를 내기 위하여 효과적으로 사용될 수 있음을 시사하였다.

$\mathrm{L} / \mathrm{H}$ ratio의 경우, 본 연구에서/오/ 모음이 가장 높았으며, 성별 및 모음 문맥 간 차이를 분석한 결과, 성별과 모음문맥 간 상호작용은 없었고, 성별과 모음 문맥에 따라 모두 유의한 차이 를 보였다. 특히, 원순모음인 /오/나 /우/에서 높은 L/H ratio값 을 보였으며, 평순모음인/이/에서 가장 낮게 나타났는데, 이러한 현상은 원순모음을 산출할 때 성도의 길이가 길어지므로, 이 때 $4,000 \mathrm{~Hz}$ 를 기준으로 고주파수에너지보다 저주파수에너지가 더 높아진다는 것을 시사한다.

\section{연결발화 유형의 효과}

본 연구에서 연결발화의 효과를 조사하기 위해 2 개의 표준 화문단을 사용한 결과, 모음과 달리, 성별과 표준 문단('가을'과 '산책' 표준화 문단) 간 $\mathrm{CPP}$ 값은 유의한 차이를 보이지 않았으 나, $\mathrm{L} / \mathrm{H}$ ratio값은 성별에서 유의미한 차이가 나타났다. $\mathrm{L} / \mathrm{H}$ ratio의 경우, $4,000 \mathrm{~Hz}$ 를 기준으로 고주파수에너지보다 저주 파수에너지 분포의 비를 측정하는 데, 일반적으로 말소리의 주 파수 영역들이 1,000 4,000 Hz에 속하며 4,000 Hz를 기준으 로 소음과 말소리를 구분하므로, $\mathrm{L} / \mathrm{H}$ ratio값이 낮을수록 음성 신호보다는 $4,000 \mathrm{~Hz}$ 이상의 소음에너지 비가 높음을 시사한 다. 하지만, 연결발화는 모음과 비교할 때 $\mathrm{CPP}$ 나 $\mathrm{L} / \mathrm{H}$ ratio값 이 유의미하게 낮았는데, 이는 연결발화과제인 두 표준문단은 모음에 비해 성대진동이 되지 않는 분절음 부분이 많고 파열음 과 마찰음, 파찰음과 같은 음소로 구성되어 있기 때문인 것으 로 여겨진다. 이러한 음소들은 공기의 파열이나 소음 및 마찰구 간을 포함하므로 더 낮은 $\mathrm{L} / \mathrm{H}$ ratio값을 보일 수 있을 것이다. 또한 두 연결발화는 서로 다른 운율과 여러 가지 모음과 자음이 결합된 다양한 음소의 문맥으로 구성되어 있는데 그럼에도 불 구하고, 두 문단은 유사한 $\mathrm{CPP}$ 나 $\mathrm{L} / \mathrm{H}$ ratio 측정치를 나타내어 유의한 차이가 없었고, 다만 $\mathrm{L} / \mathrm{H}$ ratio값에서 성별에 따른 차이 만을 나타내었다. 이러한 차이는 일반적으로 여성이 남성에 비 해 기식성(breathiness) 음질의 특성을 보여주므로, 이러한 특성
이 연결발화에서도 나타난 것으로 추측된다.

\section{모음과 연결발화 간 스펙트럼 및 캡스트럼 측정치의 상관}

본 연구에서 표준 문단인 가을과 산책문단은 $\mathrm{CPP}$ 값은 통계 적으로 유의미한 상관관계가 없었으나, 반면에 $\mathrm{L} / \mathrm{H}$ ratio는 두 문단 간에 높은 상관관계를 보였다. 본 연구에서는 연결발화의 음질과 상관성이 가장 높다고 알려진 $\mathrm{CPP}$ 값과 $\mathrm{L} / \mathrm{H}$ ratio값은 표준문단에 따라 서로 다른 모음과 낮은 상관성을 보이거나 상 관성이 없었다. 또한, 음질 평가 시 가장 많이 사용되는 /아/ 모 음은 표준화 문구로 현재 사용되는 두 문단과 $\mathrm{CPP}$ 측정치 간 상관성을 보이지 않아 음질을 측정하기 위한 대표성 모음으로 사용하기에 층분한 증거를 뒷바침하지 못하였다.

한편, 본 연구에서는 연결발화의 검사어로서 각 표준문단의 문장 전체를 분석하였으나, 각 표준문단을 구성하고 있는 모음 과 자음의 음소 형태, 음절수, 어절 길이, 주파수 영역과 같은 음성 음향학적 문맥은 구체적으로 분석하지 않았기에 이러한 특성들이 연결발화의 음향학적 측정치에 미치는 영향은 살펴 보지 못하였다. 추후 연구에서는 각 표준문단의 음성학적 문맥 을 분석하고, 음향분석에 있어서 주파수별 문맥 효과를 검증할 필요가 있다. 본 연구는 비록 적은 수를 대상으로 젊은 청년층 에 국한하여 성별과 과제에 따른 스펙트럼 측정에 대한 예비 자 료를 제공하였으나 다음과 같은 임상적 의의를 시사한다. 캡스 트럼과 스펙트럼 기반 정상 규준치는 성별 및 모음의 종류에 따 라 유의미하게 다르게 나타났으므로 임상에서 사용 시에 성별 및 모음에 따라 서로 다른 규준을 제시하여야 할 것이다. 아울 러, 정상 성인의 캡스트럼과 스펙트럼 측정치는 모음과 표준화 문단 간에 낮은 상관성을 보이므로 모음만으로 음질을 평가하 는 데는 매우 제한된 정보만을 제공할 것이다. 따라서, 후속연구 로는 표준문단 중 모음과 상관이 높은 다양한 문장을 찾아내 거나 다양한 주파수의 음성적 문맥에서 음질을 효율적으로 평 가할 수 있는 표준 문장 개발이 필요하다. 추후 연구에서는 좀 더 많은 정상인을 대상으로 캡스트럼과 스펙트럼의 연령의 효 과도 살펴볼 필요가 있다.

중심 단어 : 캡스트럼·스펙트럼·모음·연결발화·성별.

\section{Acknowledgments}

본 연구는 2013년도 정부(교육부)의 재원으로 한국연구재단의 지원을 받아 연구되었음(NRF-2013 S1A5A8024543).

\section{REFERENCES}

Awan, S. N., Giovinco, A., \& Owens, J. (2012). Effects of vocal intensity and vowel type on cepstral analysis of voice. Journal of Voice, 26(5), 670.e15e20.

Awan, S. N. \& Roy, N. (2006). Toward the development of an objective index of dysphonia severity: A four-factor acoustic model. Clinical Linguistics 
and Phonetics, 20(1), 35-49.

Bele, I. V. (2005). Reliability in perceptual analysis of voice quality. Journal of Voice, 19(4), 555-573.

Choi, S. H. (2013). Speech-language pathologists' voice assessment and voice therapy practices: A survey for standard clinical guideline and evidence-based practice. Communication Sciences and Disorders, 18(4), 473-485.

Choi, S. H. \& Choi, C. H. (2014). The utility of perturbation, non-linear dynamic, and cepstrum measures of dysphonia according to signal typing. Journal of the Korean Society of Speech Sciences, 6(3), 63-72.

Choi, S. H. \& Choi, C. H. (2015). The stability and variability based on vowels in voice quality analysis. Journal of the Korean Society of Speech Sciences, 7(1), 79-86.

Eadie, T. L. \& Baylor, C. R. (2006). The effect of perceptual training on inexperienced listeners' judgments of dysphonic voice. Journal of Voice, 20(4), 527-544.

Franca, M. C. (2012). Acoustic comparison of vowel sounds among adult females. Journal of Voice, 26(5), 671.e9-e17.

Halberstam B. (2004). Acoustic and perceptual parameters relating to connected speech are more reliable measures of hoarseness than parameters relating to sustained vowels. ORL; Journal for Oto-Rhino-Laryngology and Its Related Specialties, 66(2),70-73.

Heman-Ackah, Y. D., Heuer, R. J., Michael, D. D., Ostrowski, R., Horman, M., Baroody, M. M., et al. (2003). Cepstral peak prominence: A more reliable measure of dysphonia. The Annals of Otology, Rhinology, and Laryngology, 112(4), 324-333.

Hillenbrand, J. \& Houde, R. A. (1996). Acoustic correlates of breathy vocal quality: Dysphonic voices and continuous speech. Journal of Speech and Hearing Research, 39(2), 311-321.

Jeong, O. R. (1994). Daegu Diagnostic Aphasia Examination. Daegu: Korean Speech-language and Hearing Association.

Kim, H. H. (1996). Perceptual, acoustical, and physiological tools in ataxic dysarthria management: A case report. Proceedings on the 2nd Conference in The Korean Society of Phonetic Sciences and Speech Technology Semiannual, 9-22.

Lee, M. S. (2011). A study of acoustic measurement in connected speech with dysphonia. Speech Sciences, 3(4), 109-115.

Lowell, S. Y., Colton, R. H., Kelley, R. T., \& Hahn, Y. C. (2011). Spectral- and cepstral-based measures during continuous speech: Capacity to distinguish dysphonia and consistency within a speaker. Journal of Voice, 25(5), e223-e232.

Lowell, S. Y., Colton, R. H., Kelley, R.T., \& Mizia, S. A. (2013). Predictive value and discriminant capacity of cepstral- and spectral-based measures during continuous speech. Journal of Voice, 27(4), 393-400.

Lowell, S. Y. \& Hylkema, J. A. (2016). The effect of speaking context on spectral- and cepstral-based acoustic features of normal voice. Clinical Linguistics and Phonetics, 30(1), 1-11.

Lowell, S. Y., Kelley, R. T., Awan, S. N., Colton, R. H., \& Chan, N. H. (2012). Spectral- and cepstral-based acoustic features of dysphonic, strained voice quality. The Annals of Otology, Rhinology, and Laryngology, 121(8), 539-548.

Maryn, Y., Roy, N., De Bodt, M., Van Cauwenberge, P., \& Corthals, P. (2009). Acoustic measurement of overall voice quality: A meta-analysis. The Journal of the Acoustical Society of America, 126(5), 2619-2634.

Noll, A. M. (1967). Cepstrum pitch determination. The Journal of the Acoustical Society of America, 41(2), 293-309.

Parsa, V. \& Jamieson, D. G. (2001). Acoustic discrimination of pathological voice: Sustained vowels versus continuous speech. Journal of Speech, Language, and Hearing Research, 44(2), 327-339.

Seo, I. H. \& Seong, C. J. (2013). Voice quality of dysarthric speakers in connected speech. Journal of the Korean Society of Speech Sciences, 5(4), 33-41.

Shim, H. J., Jang, H. R., Shin, H. B., Ko, D. H. (2014). Spectral and cepstral analyses of esophageal speakers. Journal of the Korean Society of Speech Sciences, 6(2), 47-54.

Shin, J. Y. \& Cha, J. E. (2003). The system of Korean sounds. Seoul: Hankukmunhwasa.

Titze, I. R. (1994). Principles of voice production. Englewood Cliffs, NJ: Prentice Hall.

Wolfe, V. \& Martin, D. (1997). Acoustic correlates of dysphonia: type and severity. Journal of Communication Disorders, 30(5), 403-415; quiz 415416.

Wolfe, V. I., Martin, D. P., \& Palmer, C. I. (2000). Perception of dysphonic voice quality by naive listeners. Journal of Speech, Language, and Hearing Research, 43(3), 697-705. 